\title{
Project-Based Communication System Design Course
}

\author{
Gao Hongfeng, Liu Wei, Xu Suli, Ji Baofeng \\ School of Information Engineering \\ Henan University of Science and Technology \\ Luoyang, China \\ gaohongfenghappy@126.com
}

\begin{abstract}
This paper presents the implementation of communication system design course using projected-based learning method. In the project, students designed and simulated communication system in active learning ways. Communication system is interdisciplinary, which is related to knowledge from several courses such as communication principle, information theory and coding, digital signal and processing. To achieve project goals, students had to integrate the knowledge obtained in these courses. In the process of project, every student worked in a small group and tackled the difficult problems by negotiate among group members. Students' final scores depend on personal performance, group performance and final reports. Effectiveness of the learning methodology was evaluated through student's survey and comparing students' scores for 2014-2015 with that of 2013-2014. Evaluation results show that student's understanding of communication theoretical concepts is enhanced. Meanwhile, it fosters students' transversal abilities such as communication and teamwork cooperation.
\end{abstract}

Keywords-Project-Based Learning; Active Learning; Communication System; Transversal Ability

\section{INTRODUCTION}

In traditional teacher-centered design course, the role of teachers is to design environments where students can receive information. Teachers are the main resource of information. They prepare resource, designate design approach and content. Students are given tasks and do experiments following the predefined ways. When students meet difficult problems in the process of learning, teachers help to solve these problems. This traditional educational ways impress knowledge memory, not ability to solve problems. Students gain knowledge in a passive way.

Modern high education teaching methods has transformed from teacher-centered model to student-centered model[1]. Students hold the responsible for the learning process in student-centered mode. They adopt an active position in pursuing knowledge. Teachers are guides and facilitators providing the necessary means to attain the learning goals. Scores of courses not only rely on the exam scores, but also are related to whole learning process. The evaluation of learning effectiveness includes understanding of theory knowledge, personal comprehensive ability.
Project-based learning (Project-based learning, PBL) is the student-centered learning method[2]. In PBL model, teachers present real engineering projects in specific scenarios. Students have to design and finish projects by themselves. Independent tasks are assigned to students. Information collection, schemes design, implementation are in charged by students themselves. Through implementation of the project, students understand and grasp the basic requirement of every segment. Students collect and analyze information, make discoveries and report the obtained results. Students explore resources from internet, library and teachers et al. Teacher is not the main source of information. Students are no longer passive knowledge absorbers but primarily are in charge of his or her own learning[3]. When students meet problems, teachers give their advice instead of supplying answers. Students discuss and solve these problems with group peers. Through PBL, the ability of solving problems and teamwork is cultivated[4].

Communication system covers several courses such as digital signal process, principle of communication, information theory et al. These courses are strong theoretical, and are arranged in different semesters. It is difficult for students to integrate the content of these courses. Simulation of communication system is effective ways to help students to integrate concepts in the courses. Through system simulation, students can set up relation between these courses and deeply understand the abstract concepts in these courses.

In this paper, we present PBL method in communication system simulation design course. Under teacher's guidance, students build a communication system model independently, program and simulate the communication model in MATLAB language.

This paper is structured as follows: Section II introduces project context and requirement, Section III describes PBL based learning methodology. Section IV describes effectiveness assessment of the PBL based project. Section V discusses the conclusions.

\section{Project Context}

The digital communication system consists of several modules such as information source, source encoder and decoder, channel encoder and decoder, digital modulator and 
demodulator and channels. The block diagraph of digital communication system is illustrated in Fig. 1.

The tasks of the simulation project consist of design and implement these modules according to system requirements. Firstly, students have to design overall principle scheme according to the given specifications. Then they choose and determine parameters and algorithms of each module, give program flow chart. Each module is programmed into a subfunction using MATLAB program language. Finally, all subfunctions are combined together and the whole program is debugged. Statistic error probability of overall system is required to be calculated through Moto Carlo simulation.

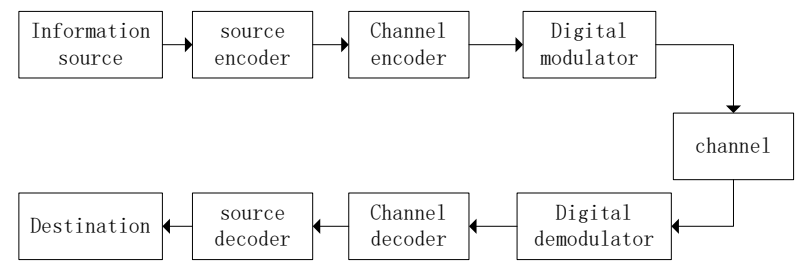

Fig. 1. Block diagraph of digital communication system

The project is arranged in the second semester of third year of university. It is planned to be finished in five weeks. Two or three students are in one group. Before this semester, the courses of communication principle, digital signal processing, information theory and coding is offered.

In communication principle course, students established the concepts of modulation, demodulation. In digital signal processing, concepts of filters and Fourier transformation were set up. In information theory and coding course, students learned source coding, channel and channel coding. The design course is arranged in the second half of the semester. Table 1 shows the relationship between the project and related courses.

TABLE I. RELATION BETWEEN THE PROJECT AND COURSES

\begin{tabular}{|c|l|}
\hline Courses & \multicolumn{1}{|c|}{ Content of Project } \\
\hline Communication principle & Design modulator and demodulator \\
\hline Digital signal processing & $\begin{array}{l}\text { Design equalizer according to principle } \\
\text { of digital filters }\end{array}$ \\
\hline $\begin{array}{c}\text { Information theory and } \\
\text { coding }\end{array}$ & $\begin{array}{l}\text { Design source coding and channel } \\
\text { coding. Established and simulate } \\
\text { common channel models }\end{array}$ \\
\hline
\end{tabular}

Before simulation, it is needed to analyze communication system thoroughly. Students should review and search professional theoretical knowledge related to the simulation progress. So that it guarantees simulation can be done successful. As most students are not familiar with MATLAB language, they have to learn MATLAB program method in the preparation stage.

Projects are divided into five stages.

1) Preparation stage: Students learn program method with MATLAB language and explore information required in the project.

2) Establishing communication system using several modules, determine parameters of these modules.
3) Programming modules of modulation and demodulation, source coding, equalizer, error correction coding respectively.

4) The whole communication system is synthesis simulated.

5) Analyze the experiment results and write reports.

Table 2 is tasks of every stage and expected results.

\section{TABLE II. TASKS OF EVERY STAGE AND EXPECTED RESULTS}

\begin{tabular}{|c|c|c|}
\hline Stage & Task & Expected Results \\
\hline 1 & $\begin{array}{c}\text { Be familiar with } \\
\text { MATLAB basic library } \\
\text { functions, selection and } \\
\text { cycle statement. }\end{array}$ & $\begin{array}{l}\text { Generate binary source, get } \\
\text { statistic performance on } \\
\text { these channels. }\end{array}$ \\
\hline 2 & $\begin{array}{c}\text { Design the whole } \\
\text { schemes, decompose } \\
\text { parameters of every } \\
\text { model. }\end{array}$ & $\begin{array}{l}\text { Types and parameters of } \\
\text { modulation and coding are } \\
\text { determined. }\end{array}$ \\
\hline 3 & $\begin{array}{l}\text { Implementation of the } \\
\text { QAM, BPSK modulation } \\
\text { mode, linear block code } \\
\text { encoding and decoding. } \\
\text { The realization of the } \\
\text { equalizer; BSC, AWGN } \\
\text { and band-limited channel } \\
\text { model programming } \\
\text { realization }\end{array}$ & $\begin{array}{l}\text { Program Implement of } \\
\text { functions of each modules, } \\
\text { which concludes } \\
\text { modulation, source encoder } \\
\text { and decoder, channel } \\
\text { encoder and decoder } \\
\text { equalizer, channel models }\end{array}$ \\
\hline 4 & $\begin{array}{l}\text { Integrate programs in } \\
\text { stage 3,and debug the } \\
\text { whole system program }\end{array}$ & $\begin{array}{c}\text { Simulation of } \\
\text { communication system on } \\
\text { several common channels } \\
\text { using functions finished in } \\
\text { stage 3, get bit error } \\
\text { probability of system. }\end{array}$ \\
\hline 5 & $\begin{array}{l}\text { Analyze the results and } \\
\text { write reports }\end{array}$ & $\begin{array}{l}\text { According to the simulated } \\
\text { statistical data, draw } \\
\text { system performance } \\
\text { curves. Compare the } \\
\text { results with theory } \\
\text { conclusion. }\end{array}$ \\
\hline
\end{tabular}

\section{PBL BASED LEARNING METHODOLOGY}

In this project, PBL based student-centered teaching method is taken. The core of PBL method is that students are fully engaged and active. Application of the method in the project produces great influence on students' learning ability. Students not only absorb knowledge, but also the solvers of problems. Teachers encourage students to innovation; actively communicate with students through questioning and discussion. Teachers help to facilitate group process and learning, not to supply answers.

In the project, students are divided into small group. Each group consists of two to three students. Every member in group is assigned different tasks and resources.

At beginning of the project, teachers give project goals and main technical specifications to each group. Group members analyze technical specifications and put forward schemes that meet requirements of these design goals. Every member in group is assigned different tasks and resources through negotiation.

At the end of each stage, teachers examined the experimental results. Students demonstrate their group work through PPT and reply to questions. In the final stage, students submit written reports. The content of reports should include 
scheme, the explanations, results, analyses completed during the five project stages.

In progress of the project, teachers play a guide role. Teachers follow the progress of project and guide them at each stage of the project. Teachers encourage students to explore the communication project actively, make them abandon the previous passive attitude.

Teachers don't supply answers when students meet difficulty. They inspire them thinking about question and encourage students discuss question with group peers. Communication theory was further validated through simulation. Students expand knowledge of communication system in practice. Under the guidance of teachers, students' ability to analyze and solve problems is cultivated through finding, analyzing and solving problem. The project cultivates students' ability to work independently, elevate their team spirit. The ability to get information and analysis and solve the problem is improved.

At the end of the course, students are expected to be able to do the following:

1) master the MATLAB programming method, improve the ability of software programming;

2) search information by looking up different sources, such as patents, scientific papers, text books, internet website etc.

3) describe the overall scheme design of communication system with knowledge of multidiscipline;

4) plan and control the progress of different stages;

5) solve problems independently in the project.

\section{EFFECTIVENESS ASSESSMENT}

The course effect is evaluated in 2 aspects:

1) The final scores of students compared to previous academic year.

2) Survey of students to the project.

\section{A. Scores Comparison Between Different Academic Years}

When the effect of the project is estimated, student performance is a widely used quality evaluated method. Teachers closely observe the changed scores of students. Assessment criteria should be closely related to the objectives of the project.

Scores of student is evaluated based on three qualitative criteria: personal performance, group achievement and final technical report quality. Personal performance is evaluated according to attendance, proactiveness, contribution to the project. Group performance is evaluated by whether the team completes the given task and the quality of the work. Technical report contains design scheme, principle, experimental results and problem analysis of each stage. Personal performance is the weight of 30\%. Group performance was $30 \%$ of the scores. Technical report was $40 \%$ of the total score.

Academic scores are divided into five grades: excellent, good, average, pass, fail.
Fig. 2 shows student scores distribution for the academic year 2013-2014 and 2014-2015 school year. In 2013-2014 year, traditional teaching methods are taken. In 2014-2015, the PBL method is taken. From Fig. 2, it can be seen that the excellent and good rate of scores was higher in 2014-2015 than that in 2013-2014.

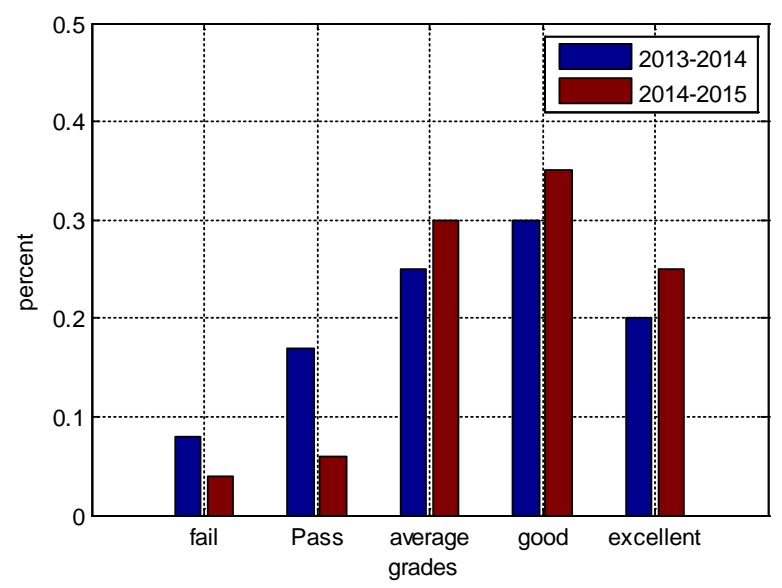

Fig. 2. The scores distribution of students in 2013-2014 year and 2014-2015 year

\section{B. Survey of Students to the Project}

The survey to students' course evaluation is taken in anonymous survey form. Students are asked 4 questions related to their personal opinions and experiences, as shown in Table 3. Students choose one answer to each question from the 5 possible answers: strongly disagree, disagree, undecided, agree, and strongly agree. The process of assessment was anonymous and voluntary. In total, all students participated in the process.

Fig. 3 is the statistic results of the survey. From fig 3, we can see that $92 \%$ of students felt that the project topic was interesting, $92 \%$ of students thought that the ability to design building blocks and systems for telecommunication was improved. 89\% of students thought this project enhances their confidents in communication engineering. $90 \%$ of students believed that the ability to communication and work in a team was enhanced.

\section{TABLE III. STUDENT SURVEY TO THE PROJECT}

\begin{tabular}{|c|l|}
\hline INDEX & \multicolumn{1}{c|}{ question } \\
\hline Q1 & The project topic was interesting \\
\hline Q2 & $\begin{array}{l}\text { Through the project, the ability to design building } \\
\text { blocks and systems for telecommunication is } \\
\text { improved }\end{array}$ \\
\hline Q3 & $\begin{array}{l}\text { This project enhances my confident in } \\
\text { communication engineering. }\end{array}$ \\
\hline Q4 & $\begin{array}{l}\text { The ability to communication and work in a team is } \\
\text { enhanced }\end{array}$ \\
\hline
\end{tabular}




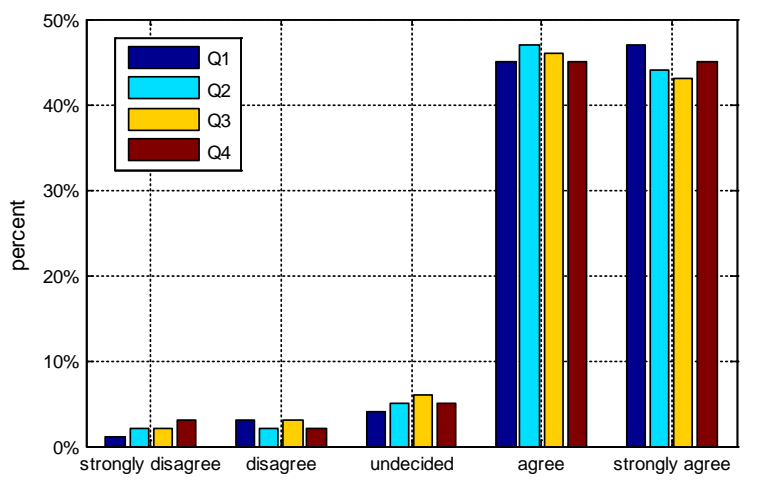

Fig. 3. Statistic results of student survey

\section{CONCLUSION}

In this paper, we give learning method of communication system simulation design course based on PBL. In the course, Students independently completed communication system design based on MATLAB. In the process of project, students search information and solve problem by themselves. Learning methodology shifted from a traditional passive acceptance to active earning in which students combine knowledge from different courses in the practical project. Simulation projects enhance students cross curricular skills; deepen understanding of real communication system and theoretical knowledge. Through searching information and cooperating with group member to solve problems, students' team cooperation and communication skills is improved. Students' scores are better than those of previous years. Satisfaction survey shows that implementation of project reached the intended target.

\section{ACKNOWLEDGMENT}

In this paper, this research was sponsored by educational reform project foundation of Henan University of Science and Technology (Project No. 2015YBZD-004).

\section{REFERENCES}

[1] MMT Valdez, CIF Agreira, CM Ferreira. Lighting design course in an electrical engineering program using problem-based learning. Eaeeie Conference, 2009:1-6

[2] H Aliakbarian, PJ Soh, S Farsi. Implementation of a project-based telecommunications engineering design course. IEEE Transactions On Education, 2014, 57(1):25-33

[3] U Meyer-Bäse, V Alonzo, A Meyer-Bäse, MS Pattichis etl. An undergraduate course and laboratory in digital signal processing with field programmable gate arrays. IEEE Transactions on Education, 2010,53(4): 638-645

[4] DG Lamar, PF Miaja, M Arias etc. Experiences in the application of project-based learning in a switching-mode power supplies course. IEEE Transactions on Education, 2012. 55(1): 66-77 